Taylor \& Francis Inc.

ISSN: $1548-7760$

DOI: $10.1080 / 15487760590953911$

\title{
How Mental Health and Welfare to Work Interact: The Role of Hope, Sanctions, Engagement, and Support JOE MARRONE ${ }^{\star 1}$, SUSAN FOLEY ${ }^{1}$ and VIRGINIA SELLECK ${ }^{2}$
}

${ }^{1}$ Institute for Community Inclusion, University of Massachusetts-Boston, Boston. Massachusetts, USA.

${ }^{2}$ Minnesota Department of Human Services, Division of Mental Health, St Paul, Minnesota, USA. *Correspondence: JOE MARRONE, Northwest Office, 4517 NE 39th Ave, Portland, OR, 97211-8124, USA, E-mail: jm61947(âa aol com

The authors wish to acknowledge the work of Melodie Pazolt and her staff at Clearview Employment Services of Columbia River Mental Health Services, Vancouver, WA and Joan Truhler and her colleagues at the Minnesota Department of Human Services, Minnesota Family Investment Program and most importantly the efforts of the clients involved in both the states highlighted that helped make these discussions relevant and timely. The writing of this article was partially supported by the National Institute on Disabilities Rehabilitation and Research Emergent Disabilities, Employment Outcomes, and Systems Change H133A021503.

This article describes some of the lessons learned in the implementation of the Personal Responsibility and Work Opportunity Reconciliation Act (PRWORA) as it relates to people with psychiatric disabilities. It attempts to articulate some of the inherent difficulties faced in serving these individuals within the welfare system as well as how the established strengths of each system can inform the other's efforts. The philosophy concerning work for clients of the welfare and mental health systems differ. Each system has developed separately, and they do not easily integrate their differing philosophies and goals. At the client level, this lack of consistency presents obvious coordination barriers. At the system level, examination of practice and the underlying philosophy of each provides incentives for cross-training and policy changes. Two case studies describe the identification of issues, opportunities, and challenges to providing Temporary Assistance for Needy Families (TANF) services to individuals with mental illness. These lessons can provide guidance to mental health systems as they strive to implement evidence-based employment practices and provide welfare entities with policy direction as a result of a widening knowledge base. Specific policy and program innovations in a county and in a state are highlighted to demonstrate these issues. Finally, the authors raise areas for further inquiry and reflection.

Keywords: Employment supports: Mental health: System change; Welfare reform.

Several major federal legislative reforms have sought to restructure the state systems responsible for services to people living in poverty and dependent upon government income supports or users of public employment services. Among the most publicized and dramatic change that has occurred within social welfare programs, has been The Public Law 104-193, the PRWORA of 1996. PRWORA has been variously viewed as a success for sweeping social and economic change, but, at the same time, as a failure because it was unable to address the true factors of poverty and it eliminated the federal "floor" supporting welfare programs. Yet, it created a 
platform that encouraged policy makers, researchers, advocates, and TANF agencies to reconfigure their state welfare programs.

Welfare policy changes have created 51 laboratories as each determines how to structure welfare programs to reduce the rolls and to increase the number of people returning or entering work. The work requirements associated with TANF have highlighted another issue. Among individuals who receive welfare assistance, significant portions of them not returning to work are also affected by a psychiatric disability.

At the same time, the public mental health system is increasingly charged with implementing evidence based practices into its service delivery paradigm (Carpinello, Rosenberg, Stone, Schwager, \& Felton, 2002; Corrigan, Steiner, McCracken, Blaser, \& Barr, 2001) and is being asked to include employment outcomes within the panoply of service outcomes for which it takes some responsibility (Drake et al., 2001). Shrinking resources at the state level have created further incentives to support demonstrably effective service methods. Indeed, this is one of the few paths open to policy makers that have broad appeal both philosophically and to legislators eyeing the bottom line.

The systemic change in philosophy and the results achieved in welfare reform implementation holds many lessons for those in the mental health and rehabilitation employment policy fields. These changes in the welfare system, as well as in the mental health system have should lead to an increased emphasis on a collaborative approach to employment for individuals in this not so unique situation.

As PRWORA is now in the process of being reauthorized, heated discussions are occurring at many levels about the role of increased levels of required work activity for TANF recipients and about policies around whom, if anyone, to allow exemptions from these work mandates.

While there are many examples that illustrate people with significant psychiatric disabilities can work (Becker et al., 2001; Marrone \& Golowka, 2000) employment as a mandated outcome within mental health systems of care remains controversial (Marine \& Galloway, 2000). Disability advocacy for employment has repeatedly emphasized the untapped working capacity of people with disabilities. However, few, if any, mental health systems espouse the unalloyed view that people with mental illness do, in fact, have to accept personal responsibility to choose employment-a view that PRWORA unequivocally supports for TANF recipients.

\section{THE NATIONAL PERSPECTIVE: GOALS, POPULATIONS, AND PROBLEMS}

As these parallel systems have developed and successes have been noted, many are recognizing the overlap in populations, the limitations of each system's resources, and the potential to achieve their own independent outcomes through collaborative initiatives (Foley, 2002).

\section{Goals}

Welfare and mental health systems tend to have different views on the expected outcomes of their respective services. The poverty system grew out of an effort to assist families headed by a single parent (almost always assumed to be the mother) in surviving, and has changed into a transitional program that offers services to assist families in achieving self-sufficiency. Efforts to infuse work requirements have waxed and waned throughout the decades in welfare policy and were often applied to segments of the welfare population differently depending on who was determined to be deserving of benefits (c.f. Abramowitz, 1996). This transition was sponsored through a series of federal reforms that emphasize the importance of work and redefining public welfare as a shortterm, time-limited program and not a permanent source of on-going financial support 
(Nightingale, Pindus, \& Trutko, 2002). Reforms culminated in the enactment of PRWORA in 1996.

The mental health system is charged with the primary responsibility for providing social and clinical services for people with serious psychiatric disabilities. Some mental health agencies offer vocational services; others refer people to the state vocational rehabilitation (VR) agency. Many mental health programs (especially over the last decade) have begun providing some employment services for a portion of their clients, who may or may not be simultaneously served by the VR system. Recently, mental health systems have focused on expanding activities to provide, fund, or regulate employment services for their service recipients and on coordinating more closely with the state-federal VR system. Both agencies continue to debate the employability of people with significant mental health disabilities and, in the case of public mental health systems of care, whether work as an outcome is desirable.

An outgrowth of the emerging collaboration between welfare and psychiatric disability services staff is at a heightened level of confusion about the roles of each as it pertains to providing rehabilitation-oriented services to mutual clients. Below are quotations from people who are trying to help the remaining individuals receiving TANF return to work. These statements were all uttered throughout the course of training sessions conducted to assist the Minnesota Department of Social and Human Services in developing an assessment and screening process for identifying mental health needs in the TANF population:

- "Well, if they're disabled, why don't we just help them get on Social Security?"state level welfare staff

- "Social Security! If we send them there, we 're dooming them to a life of poverty and unemployment!"-state level disability policy staff

- "What's the problem with just writing an exemption from the work requirements? Work is too stressful for people with mental illness. "-community mental health counselor

- "You want me to ask people about their mental health problems! What if they break down in my office?"-TANF provider

- "These mental health screening questions are too personal-their mental health isn't my business, getting them a job is my business. "-TANF provider

- "You have to be VERY careful when you do anything that might imply that someone has a mental health problem!"-an advocate

- "If her ex-husband finds out she has mental illness, he 'll get the kids!"-TANF provider

The remainder of this article will focus on why these statements manage to convey not just individual sentiments but reflect systemic challenges in assisting TANF recipients with psychiatric disabilities to successfully exit the TANF rolls. However, these conundrums also present opportunities for cross system fertilization and joint learning between welfare and mental health systems of care

\section{Prevalence of Psychiatric Disability in the Welfare Population}

The U.S. Centers for Disease Control (CDC) estimates that $8 \%$ of the U.S. adult population experience "frequent mental distress" (defined as being in poor mental health for more than 14 days out ot the previous 30) at any point in time (CDCI, 1998). Such individuals are more likely to possess one or more of the following characteristics: unemployed, poor, female, separated, and poorly educated (CDC, 1998). All factors which are intrinsically tied in with being on TANF for 
long periods of time. The United States General Accounting Office (GAO) estimates that about half of the people currently receiving welfare are people with disabilities (GAO, 200I). In a subsequent report, nearly 25 percent of the 700,000 child-only welfare cases were families headed by an adult receiving social security or supplemental security income (GA0, 2002a). Reports from the Center on Budget and Policy Priorities and the Urban Institute estimate the number of people receiving welfare who have a serious mental health problem to be between one fourth and one third of the population (Sweeney, 2000; Zedlewski, 2003, 1999). Approximately one-fifth of those who have left TANF and are not working have mental impairments and almost half of parents in this group either said that they were in poor general health or scored low on a standard mental health scale (Sweeney, 2000). Zedlewski (1999), using the National Survey of American Families, found that one-fifth of nonworking former recipients scored very poorly (in the bottom 10 percent) on the mental health scale. In a follow up study in 2002 (Zedlewski, 2003), the proportion of the TANF caseload that reported poor physical and mental health as a significant barrier was over one third and similar to the 1999 reported figures. As many as onefourth to one-half of the parents no longer receiving TANF due to a sanction in the early implementation phase of PRWORA indicated an inability to comply because of a disability, health condition, or illness (Zedlewski, 1999).

Many states documented mental health disability among their respective welfare populations prior to welfare reform. Michigan found nearly one-quarter had major or clinical depression; about one-seventh had post-traumatic stress disorder or general anxiety disorder (Danziger, Corcoran, \& Danziger, 1999). Utah found similar rates for post-traumatic stress and general anxiety and about two-fifths had major or clinical depression (Barusch \& Taylor, 1999).

The 1998 Washington state TANF agency's report found that more than $25 \%$ of TANF recipients experienced some form of diagnosable mental illness for which they sought treatment in the previous year (Washington Department of Social and Health Services, 1998). The Minnesota TANF agency found similar disability rates to Washington (Minnesota Department of Human Services, 1999). In a more recent six state study of TANF recipients conducted by the U.S Department of Health and Human Services (Hauan \& Douglas, 2004), mental health problems were cited as especially common, with nearly one-third of all respondents across the six sites meeting the diagnostic criteria for major depression or experiencing serious psychological distress

\section{Problems}

The magnitude of the problems facing these recipients is clear. Solutions are less obvious as they involve the interplay of clinical, socioeconomic, demographic, political, and systemic factors. Yet some programmatic guideposts do exist for remedies, based on social science and psychiatric rehabilitation research conducted over $20+$ years, in supporting people with major mental illnesses in surviving and thriving in the community.

Cross-system innovation and service delivery alignment are necessary steps in tackling implementation problems connected to supporting people with multiple disadvantages and barriers to work. A significant system barrier is a lack of clarity of whether people with mental illnesses can and should work. Unfortunately, this lack of clarity, at least in the past, has come from mental health professionals who fear that work is too stressful for people with mental illnesses. In spite of this fact, researchers have not found a link between working and relapse. In fact, some studies find an association between work and improved mental health (Drake, Becker, Biesanz, Wyzik, \& Torrey, 1996; Drake, Becker, Clark, \& Mueser, 1999).

Barriers caused by differing missions, cultures, funding streams, and structures among parts of the public social services system are not news. These rifts are exacerbated when it comes to mental health and welfare systems interacting. Recipients of services and their families are 
routinely forced to be unwilling emissaries across the abyss between the many parts of the social service system. People are often motivated to navigate the process to get resources and help; but in the case of mental health assessment and treatment, they often do not want to go, and parts of the system are afraid to send them. At the same time, not all people with mental health issues need special help to get to work. It is likely, however, that many individuals who remain on the welfare rolls are having their efforts toward self sufficiency complicated by a mental health barrier.

This article describes problems two states in coordinating services across Mental Health and TANF systems: a) identification of people with psychiatric disabilities within the welfare system (Minnesota) and b) case management issues in working with people with psychiatric disabilities referred from welfare agencies to mental health employment services (Washington). These dilemmas are highlighted through the use of specific examples of state level and local service delivery interventions and strategies. These programs are described more fully below. In Minnesota, a significant statewide effort is underway to screen TANF recipients for psychiatric disability. Many states are developing their own screening tools, borrowing from other states, or evaluating the benefit of screening. The effort is time consuming, complex, and politically charged. In Washington, a community mental health provider seeks to offer employment services to people with psychiatric disabilities served by the welfare and mental health systems. Mental health providers offering vocational services to people receiving welfare become critically aware of the implementation obstacles created by two distinct policies.

\section{Identifying People in Minnesota: Screening and Assessment}

Cross divisional/departmental collaboration efforts have focused on finding people with mental health and/or chemical dependency (CD) barriers so they can be helped to use the welfare supports to self-sufficiency before the time limit. Minnesota piloted and uses a screening tool to help Minnesota Family Investment Program (MFIP - the state realization of the federal TANF system) identify those in need of a professional mental health or CD assessment. The screening tool originally was used only after a person has been in the system for a period of time and was not making progress in his/her employment plan. Currently, the MFIP system now screens people sooner (after 8 weeks in the system) and they can give extensions for mental illness and other disabilities only if the person complies with treatment.

In the pilot phase conducted in 2003-2004, over 800 people were screened and $63 \%$ scored in the range indicating need for professional assessment. Actually obtaining the assessment, even though it was a covered Medicaid service, proved quite difficult because of resistance on the part of the recipient and system linkage problems. Of the 148 people who were professionally assessed by end of 2004 , nearly $100 \%$ were diagnosed with a disorder. Other findings from the pilot study indicate that

1. Employment counselors were often reluctant to use the screen because of fear of stigma. One of the authors routinely asked in training sessions with employment counselors working with TANF recipients: "What would you do if a client in your office complained of chest pain and shortness of breath?" Of course, there is universal endorsement about getting medical assessment at once. But when a person acknowledges feelings of hopelessness, thoughts of self-destruction, sleep and appetite disturbance, "We do not want to offend them by suggesting they might have a mental health problem;"

2. Recipients often do not want to acknowledge these mental health issues. If they do acknowledge them, they often refuse professional mental health assessment 
(even while knowing they can have their TANF grant reduced if they do not have it);

3. Persons are even less likely to endorse items directly acknowledging a chemical dependency issue than the presence of mental health distress but subsequent professional assessment often reveals its presence; and

4. The advocacy community is very concerned about labeling an individual "mentally ill," and is very watchful of the screening process. This concern is fueled by issues related to breach of client confidentiality, inadequate protections about how the information might be used, apprehension about the qualifications of the staff using the screening tool, and parental worries about potential involvement of child welfare authorities. These objections were noted and essentially overcome through involving advocates in both the final approval of the screening tool to be used, the process of how it is used, and review of the overall data obtained with reporting of assistance rendered by the MFIP authorities subsequent to a "positive" screen.

Continuing efforts to quantify the problem of people with mental health and CD barriers continue. Minnesota has begun to use administrative data to match the overlap of TANF recipients using mental health services or psychotropic medications. During the time frame studied, $58 \%$ of the MFIP sample had already received either a Medicaid funded mental health service or psychotropic medication. This situation is one that is present to some extent in all the states, but one which the Minnesota Mental Health and MFIP state level personnel addressed directly in the meetings related to why they felt the screening tool was needed.

\section{Case management issues after referral: Clearview Employment Services of Columbia River Mental Health Services, Inc. in Washington State}

Clearview Employment Services is a program of Columbia River Mental Health Services providing clinically integrated employment services as part of the overall system of care in Clark County (Vancouver), WA, which lies across the Columbia River from Portland, OR. Services through Clearview include: career counseling, vocationally related case management, support, job coaching, vocational assessment, and/or job development. Clearview helped over 129 people served through the mental health in fiscal year 2002 to obtain employment

Clearview's service design essentially followed the precepts of the evidence-based practice of Supported Employment as exemplified in the Individual Placement and Support model developed by Drake and colleagues of New Hampshire Dartmouth Medical Center (Drake et al., 1999). Using this formula, Clearview planned to assist people who were long-term welfare recipients and had barriers to employment related to mental illness and/or substance abuse through a local Welfare-to-Work (WtW) contract. The original design called for serving 80 of the "hardest to serve" (by federal definition, those on TANF at least 30 months and facing multiple barriers to self sufficiency) recipients and helping at least 40 get jobs. After two years of operation the program served well over 100 people, and helped over 70 get permanent employment. A screening tool, developed by local mental health agency staff was provided to TANF personnel. The purpose was to allow them to identify people who might benefit from referral to the program, not necessarily to initiate a thorough diagnostic mental health assessment, though clients were offered this as a service if they were so identified. Initially it was assumed individuals who fit the WtW criteria were similar to those served in the mental health system.

When Clearview first received funding, it wanted to target individuals within its parent community mental health agency. This proved much more problematic than initially thought for a 
variety of reasons. The majority of the mental health staff was not aware of clients" financial issues/funding, the policies surrounding the state implementation of welfare reform, or the federal requirements attached to PRWORA. Over $50 \%$ of the clients served through the TANF project were already involved with the public mental health system at the time of referral from the Washington TANF agency to Clearview, either as primary or secondary (i.e., their children were receiving services) consumers of the mental health system of care.

Initially Clearview employment staff believed that individuals all would exhibit the inherent desire to work. This was quickly challenged as TANF clients engaged in power struggles with financial workers to keep their checks. It seemed as though people consistently gave excuses related to medical and psychological reasons saying that they were unable to work. This has been anecdotally reported in other states as well. This kind of exemption was intended to provide a cushion to people in truly difficult circumstances. In effect, this cushion, because of its broad parameters, provided an inducement to claim disability as a mechanism to escape work rather than as a protection for people who cannot work. Disability exemptions as defined were flawed because they were based upon a theory that disability is automatic justification for not working and ignored the availability of vocational interventions and supports for people with disabilities.

Certain characteristics of the welfare recipient were in stark contrast to the population of people with mental health illnesses that came through the mental health center. The latter were usually voluntarily seeking employment. The welfare agency instigated a referral to a vocational program for beneficiaries with mental health conditions and the resulting referrals included people who were not necessarily self-directed toward employment. Whereas, the mental health system of care did not mandate employment services but referred those who expressed an interest in employment. Moving towards employment was an explicit expectation of PRWORA; however, work was not (and still is not) a clear expectation of clinical intervention within a mental health system of care but rather an opportunity for those who choose to seek it out. Thus, the question clearly was raised: Was the disability the employment barrier? Or, was it system expectations, inducements, and availability of supports?

Service delivery implementation issues arose that were attributable to levels of cooperation, power struggles, and cross-system inducements. Clearview staff used a person-centered approach to service delivery that developed through vocational rehabilitation theory. Staff would emphasize strength identification and establishing conditions and environments conducive to the success of a jobseeker with active psychiatric symptoms. Job seekers may have unrealistic goals, but it was the job of the staff person to work within a vocational development process that would identify threads from those goals that could be achievable. Goals were not confronted as unrealistic but rather as a normal part of the vocational development process.

Many clients were not there voluntarily, thus, excuses and outright refusal were common and dashed most of the possible lines of vocational inquiry tried. Clearview staff observed that these clients skipped from goals to expectations and turned-down jobs that did not match exact conditions. Expectations could be difficult for staff to meet and nonnegotiable. Although the difference between goals and expectations may be subtle, in practice, they are significant. One may have a goal to be a paralegal and strive to work toward that goal. But, if one will only accept paralegal jobs immediately without ever working or getting trained in legal studies, then it may be an attempt to defray work.

Power struggles were also evident between the person receiving welfare and the TANF case manager. Each client identified and formally agreed to a plan that contained concrete steps for work activities. Clients had to provide documentation or prove that they had accomplished the steps. Failure to do so would result in sanctions. If an individual claimed that they were unable to participate in the activities identified on the plan, they would need to provide the documentation of such issues as medical or psychological conditions. Some individuals did get jobs just to get 
"off" the system rather than getting into struggles with TANF staff over whether their conditions were trivial or malingering.

In a more clinical vein, Clearview employment staff were concerned about clients displaying fears that the TANF agency was against them. Clients would sometimes cause friction between mental health and TANF staff. This behavior is often referred to, in therapeutic terms, as "splitting," and results in staff feeling the need to "rescue" the client from the other system. One side is typified as bad and the other as good. The assumption is that the client was using this as a strategy to cause confusion and thus enable him/her to avoid needed change. An interesting observation in the Washington demonstration was that, in some ways, the tension was caused by some role reversals of the traditional roles of MH and TANF staff. The Clearview Employment staff held an unequivocal belief that all people can and should work, while some TANF staff were looking to Clearview to provide them data justifying that the person should be exempted from work activity.

The more agencies involved with a family, the more opportunities for a client to engage in what professional staff described as "manipulative" or more accurately "dysfunctional" behavior and become overwhelmed by the responsibilities indicated on the plan. Frequently, each agency had a separate direction or tasks for the client to complete. Anxiety and emotional dysregulation were evident through many of the interactions that were observed with clients in the Washington project. Though what these staff observations were not able to discern was cause and effect relationships between the difficult and complex situations TANF clients found themselves in and the occurrence of these behaviors. More simply put, it is unclear from the Clearview experience in Washington whether such conduct was a logical response to a dysfunctional human service system or whether the people referred tended to fall into these clinical categories. Part of the virtue of Clearview's position as part of a comprehensive mental health center was easy access to mental health diagnostic assessment. However, most clients, if they were not already engaged in treatment, did not choose to avail themselves of this option and when it was rendered, it often led to the clash in cultures between the mental health tendency to try to "exempt" and "protect" and the TANF "mandatory work activity" formulation.

Clearview had the opportunity to walk on both sides of the fence. To the TANF agency, it was providing a service and had to become acquainted quickly with the guidelines of welfare reform. To the mental health center it was a part of their agency, staffed by mental health workers. As the two worlds collided, Clearview staff observed quite a few differing perceptions between the agencies. Originally, the local TANF agency was hesitant to refer to the Clearview program, as its staff perceived the mental health system as enabling and protecting clients. Conversely, many clinical personnel within the mental health agency felt that people were being forced back to work who were not yet ready or prepared. These differing views caused Clearview staff to feel "caught in the middle," as several of its employees described it. The first several months of the project were spent overcoming the TANF agency"s perception that Clearview was going to help individuals with an overly protective approach rather than a work search orientation and that the program would not communicate fully with them. The mental health center was viewed as a "black hole," where clients were referred and were never heard from again. Communication about a person's treatment progress, participation, or information about whether they were accepted into services was uncommon among most TANF agency staff. TANF social workers would identify an individual they believed might have symptoms of mental illness and refer that individual to the mental health center. They perceived that that person was accepted for services, would receive intensive treatment, become cured, and return to the work search. During this time of treatment, the client would be deferred from a work search activity that was "counted" as a quantifiable employment-related outcome. As the project progressed, local TANF caseloads came under increasing scrutiny from state administrators, which translated into increasing pressure for local staff's moving more of their clientele into easily quantifiable work search activities. 
Even though the welfare system and the mental health system clashed on several levels, Clearview was able to assist in the communication process between the agencies. It was able to help some clients gain access to and others use more effectively needed mental health services. Clearview also facilitated a communication system from the point of entry into the local mental health system of care. Regular dialogue was established through reporting and frequent meetings at both the direct service and supervisory levels of both agencies in order to facilitate information flow. Clearview personnel acted as liaisons to both systems, which allowed them to complete case staffings, report on a person's progress, and describe a person's environmental issues of which therapists may not be aware.

\section{Policy Implications and Recommendations Gleaned From These Examples}

Is it possible to create a philosophical fusion of all of these apparent contradictions? There are a number of strategies that can be used to help staff to surmount barriers that exist.

Increase the expectation that work is an achievable goal, a social responsibility, and a healthy behavior for people with psychiatric disabilities.

While major systemic reforms, training, and interagency linkages are crucial pieces of the change strategy required, the need to assist individuals (staff, clients, providers, and others) to reframe their personal view of the world cannot be ignored. Work, historically, has not been a major focus of mental health outcomes and this complicates the personal change process in which welfare recipients with psychiatric disabilities must engage. As one recipient with mental health problems stated at a national meeting on helping people with disabilities move off public assistance: "By the time I applied for public assistance I already decided I was a self-identified failure, so I needed to and wanted others to help me deal with that self image at the same time they were asking me to get a job and leave public assistance behind."

Professionals in systems often ascribe lower standards of achievement in many areas of life for people with mental illnesses, whether they are on public assistance or not. They point to such factors as "severity of the disability" or "system disincentives" as the major reasons for such expectations. It is now time for staff in both mental health and TANF systems to consider the possibility those minimal expectations for achievement, diminished capacity for hope and positiveness, and lack of systemic accountability for poor performance of staff members and programs are major obstacles for changes in individuals.

Before hope can be instilled in program recipients, it must first be instilled in the staff. Program supervisors must insure that staff have an awareness of the Rehabilitation and Recovery approach, including systematic exposure to people who have actually recovered. A 2002 GAO report (GAO, 2002b) describes the work outcomes across a broad population, (i.e., TANF recipients) with many barriers. As barriers go up in number, work outcomes diminish; however, more than $50 \%$ of those studied with two or more barriers were meeting work expectations. A corollary to the need to create a greater sense of "hope" in recipients is the concurrent obligation to help people move out of what seems an inevitable status quo of economic stagnation by a strategy that includes "hassling." Hassling, although an informal term, is used to imply that individuals and systems require both internal and external motivators to change the status quo in their situations. This includes challenging current beliefs and behaviors.

Supported employment technology transfer

The knowledge base on employment of people with mental illness must be integrated with the efforts to support recipients with mental illness to get and remain off TANF. There is scant evidence that empirical supported interventions such as individual job 
development, ecological job matching, and ongoing support have been adopted in most of the PRWORA funded employment services

The transfer of supported employment technology to the welfare population with psychiatric disabilities is not without challenges. For the most part, this technology was developed with an assumption of voluntary participation by the jobseeker. This is not always the case for people referred by welfare to an employment program with specialty in psychiatric disability. Many individuals feel stymied, in despair, or have little motivation to change. Other individuals are simply opposed to working for a variety of reasons. As alternatives for "getting out of work" are fewer, disability exemptions become a viable alternative for an individual who does not wish to work. The bottom line will be whether welfare believes psychiatric disability is in and of itself justification to exempt a person from work requirements. While this is not to say that no one should ever get an exemption due to health or psychiatric issues (extreme situations do exist), we argue that the assumption of inability to work is a prejudice not founded on any science, experience, or legitimacy. There is much science supporting the opposite assertion: people with psychiatric disabilities, even serious psychiatric disabilities, can work.

Focus on the goal rather than on the process.

Much has been written within the business literature about the importance of changing behavior as a precursor and a stimulus to changing values rather than vice versa (Beer, Eisenstat, \& Spector, 1990; Marrone, Hoff, \& Gold, 1999). Welfare reform has had a more drastic effect on how welfare (especially TANF) services are delivered than evidence based practice in mental health (Sanderson, 2002) or supported employment generally in the disability world (Mank, 1994) has had on their respective service systems. Many advocates argue that rehabilitation services that focus on employment are medically necessary (and therefore Medicaid reimbursable) particularly if they remedy the sequelae of mental illness to obtain functioning. If this reasoning is accurate, then the time may have come for a federal mandate for state MH systems of care to incorporate employment as an expected, reportable outcome for systems of care. The Center for Mental Health Services is moving gingerly towards this eventual goal by requiring (beginning in the 2004 fiscal year) states to report on employment outcomes of clients served within the public mental health system as a condition of receipt of mental health block grant funding. Despite this mandate, no extra funds to enable this work appear to be forthcoming, and there continue to be prohibitions on the use of Medicaid for certain parts of evidence-based, supported employment practice. Thus, this expectation continues to be complicated due to the localized nature of most mental health system funding and the complexities of Medicaid fiscal mechanisms and waivers; yet it needs to be explored more fully. However, the connection between employment services and medical services is not without challenge. The medical model is not viewed as an ideal construct for the delivery of employment services and other nonclinical supports to people with disabilities (Hagner and Marrone, 1993). Continuing to fund employment services as a "waiver" of existing authority, rather than as a focused funding stream, inherently devalues them.

Colocate mental health, chemical health, and welfare services in the same office.

This strategy reduces the complexity of making referrals and is less intimidating for recipients. Even in the absence of formal colocation, the Washington project spent much time creating interaction opportunities for staff from different systems, including scheduling staff tours, joint periodic informational meetings of direct service and supervisory personnel, weekly case staffings, and consistent communications that disseminates programmatic and client information. But proximity, in and of itself, does not cross the philosophical and service intervention divide (or more appropriately, 
chasm). The leadership in all systems must reward, rather than discourage, collaboration among staff; And then work to identify and remedy program rules that negatively affect integrated service delivery that leads to employment outcomes for people with psychiatric disabilities receiving welfare benefits. Small issues such as how to count work activity if a person is not in a classroom can lead to big problems in getting someone to actively seek work.

Intensive cross training of staff in all areas is essential.

Job seekers with psychiatric disabilities who receive welfare require competent caseworkers that understand multiple service systems if the job search is to be successful. Critical competency areas include:

- Information about system values and practices;

- Overview of clinical and functional characteristics associated with relevant mental illness diagnoses (e.g., clinical depression, post traumatic stress disorder);

- Basic knowledge of PRWORA philosophy and opportunities for discussion about the underpinnings of this major paradigmatic shift;

- Information about the prevalence and incidence of mental health problems within the TANF population;

- Information about evidence-based, best, and promising practices in recovery, rehabilitation, and employment for people with mental illness for both TANF and mental health professionals; and

- Innovative collaborative activities among TANF, mental health, rehabilitation, and workforce staff nationally.

Training should be ongoing as staff turnover and the complexity of the information increases the need. For the most part, caseworkers in both systems are paraprofessionals with baccalaureate or associates level education. They are not clinical personnel and may need specific guidance on how to interact with people with psychiatric disabilities, motivate them, and recognize a behavior attributable to a disability rather than "problematic client" behavior and avoid dynamics such as "splitting."

Assess to identify supports, not to screen for problems

The goal of assessment should be to determine the concrete supports that will assist the person, as he or she presents, to become employed. Many states are focusing more heavily on "screening tools." Screening is of limited utility, particularly with psychiatric disability, in that it identifies problems but does not identify strategies to overcome them. Recent assessment efforts in welfare have been to assess barriers and deficiencies and to look at what further training is needed to make people job ready. Considerable interest, particularly in the form of research initiatives, has focused on identifying the number of barriers and their relationship to employability. While this defines the particular characteristics of a subsample of a large population, it does not instruct a caseworker on how to work with the individual person of concern. The discussion on disability in an environmental context has application, and rehabilitation approaches to assessment have potential for both mental health and welfare agencies, that is, looking at capacities, skills, and interests and finding out what type of work the person is ready for now. It also may prove to be an area for collaboration among mental health, welfare, vocational rehabilitation, and workforce development programs in obtaining nontraditional employment for people with atypical skills (Foley, Marrone, \& Simon, 2002). 


\section{Integration of Services, Not Just Coordination}

Federal and state policies should be developed to support integrated funding. Clients with multiple needs draw from many funding sources and the challenge of putting together services is great. The desirable outcome is seamless (from the client's view) service delivery. The use of "Wraparound" service delivery in youth mental health programming illustrates the powerful potential impact of such comprehensive service stream integration (VanDeBerg \& Grealish, 1996). Needless to say, many powerful institutional forces then come into play to protect funding bases and agency "turf," especially in times of diminishing federal and state fiscal support, and thus serving as impediments to the expansion of such blended or braided funding strategies.

Examining the numbers and types of work activity required for TANF clients with psychiatric disabilities

Whether people with significant mental health problems can move as readily into fulltime employment as those without such problems is open to debate. Historically, it appears that people with mental illnesses have difficulty working full-time (Cook et al., in press). What is not as clear is whether this is a characteristic of the illness itself or of the inadequacy of services and supports targeted to achieve this end. Twenty and thirty hours of work activity is a concrete expectation of work measured on a weekly basis and tied to consequences. The authors find this laudable, but it presents a quandary. One the one hand, if a person cannot achieve the hours due to a disability, is it too punishing to sanction for noncompliance? Acute flare-ups of a condition, sedating medication, and mandates for therapy by other systems (such as child welfare) may limit hours per week available for work. On the other hand, lowering the hours is tantamount to reducing expectations. Counting therapy as work is a way to balance this problem, but it is a dangerous message to send to a person learning to adapt to the work world. Therapy is not work and employers do not consider it part of a job description. Perhaps a person could "bank" hours one week if they cannot achieve hours in an upcoming week? Averaging 20,30, or 40 hours of work per week over a period of months provides more flexibility than a mandate per week. It also mirrors the work schedules of those in jobs with fluctuating weekly hours such as the self-employed workers, seasonal workers, temporary office workers, artists, and service workers. Flexible is not a synonym for lax. Without such an option, state agencies may find themselves facing a "Hobson's Choice:" (a) exempt everyone who can not make the work hours due to disability or (b) sanction everyone regardless of good faith effort to achieve work. Option (a) is a low expectation. Option (b) does not recognize the cyclical nature of disability and may in fact exacerbate feelings of hopelessness and failure despite good faith efforts. There is a role for sanctions and a need for consequences.

Examining the role of employment and social supports

Supported employment techniques as developed through early iterations of welfare and adapted through VR may have significant implications for post employment supports (Foley, Marrone, \& Simon, 2002). Job supports that include a coach, mentoring, natural supports, and career development may help a newly hired person find stability on the job. Other areas to explore are creative problem-solving and self-monitoring of mental health issues or symptomatology. If people do not have more influence and involvement in the development of supports, they will not learn how to manage the bumps in the road later. Individuals should acquire the resources to seek services from their employer, community, and other private individuals prior to welfare. People should not be dissuaded from seeking mental health system help, but once having done so, should be encouraged to see themselves as competent beings who can mobilize a range of 
professional and personal supports. Adopting a Recovery approach supports growth and competence.

\section{CONCLUSION}

Mental health advocates would be doing a great service to inquire how systems are collaborating to support work efforts of people with mental illness in the welfare system. It cannot be said too often: People with mental illness can and should work, but all systems must learn to provide the needed supports to permit success. This should include the acceptance of mental health problems as part of many people's lives, problems that can be helped, not fearsome secrets. Furthermore, the system must be willing to accept not merely the presence of mental illness as a reality in the lives of many long term TANF recipients but also the responsibility to use proven systemic and clinical psychiatric rehabilitation and recovery strategies that help such people move from welfare and mental health system dependency to individual financial, career, and personally fulfilling success.

\section{REFERENCES}

Abramowitz, M. (1996). Regulating the Lives of Women: Social Welfare Policy from Colonial Times to the Present (revised edition). Boston: South End Press.

Barusch, A.S. \& Taylor, M.J. (1999). Understanding Families with Multiple Barriers to Self Sufficiency: Final Report. Salt Lake City: University of Utah Social Research Institute(http://www socwk.utah.edu/finalreport.html).

Becker, D.R., Bond, G.R., McCarthy, D., Thompson, D., Xie, H., McHugo, G.J., \& Drake, R.E. (2001). Converting day treatment centers to supported employment programs in Rhode Island. Psychiatric Services, 52, 351-357.

Beer, M., Eisenstat, R., \& Spector, B. (1990). Why change programs don't produce change. Harvard Business Review, November-December, 158-166.

Bond, G.R., Becker, D.R., Drake, R.E., Rapp, C.A., Meisler, N., Lehman, A.F., Bell, M.D., \& Blyler, C.R. (2001). Implementing supported employment as an evidence-based practice. Psychiatric Services, 52(3), 313-322..

Carpinello, S.E., Rosenberg, L., Stone, J., Schwager, M., \& Felton, C.J. (2002). Best practices: New York State's campaign to implement evidence-based practices for people with serious mental disorders. Psychiatric Services, 53(2), 153-155..

Centers for Disease Control (CDC). (1998). MMWR: Self-reported frequent mental distress among adults-United States, 1993-1996. May 1, 1998. 47(16), 325-331. Atlanta, GA:

Author.

Cook, J.A., Carey, M.A., Razzano, L.A., Burke, J., \& Blyler, C. (2002). The pioneer: The employment intervention demonstration program. New Directions in Evaluation, 94(I), 3I44.

Corrigan, P.W., Steiner, L., McCracken, S.G., Blaser, B., \& Barr, M. (2001). Strategies for disseminating evidence-based practices to staff who treat people with serious mental illness. Psychiatric Services, 52(12), 1598-1606.

Danziger, S., Corcoran, M., \& Danziger, S. (1999). Barriers to the Employment of Welfare Recipients. Ann Arbor: University of Michigan Poverty Research and Training Center (http:/www ssw.umich.edu/poverty/pubs.html). 
Drake, R.E., Becker, D.B., Biesanz, J.C., Wyzik, P.F., \& Torrey, W.C. (1996). Day treatment versus supported employment for persons with severe mental illness: A replication study.

Psychiatric services, 47(10), 1125-1126.

Drake, R.E., Becker, D.R., Clark, R.E., \& Mueser, K.T. (1999). Research on the Individual Placement and Support Model. Psychiatric Quarterly, 70(4), 289-301.

Drake, R.E., Goldman, H.H., Leff, H.S., Lehman, A.F., Dixon, L., Mueser, K.T., \& Torrey, W.C. (2001). Implementing evidence-based practices in routine mental health service settings. Psychiatric Services, 52(2), 179-182..

Foley, S.M. (2002). Preliminary findings from national survey of state systems and employment Paper presented at the Council of State Administrators of Vocational Rehabilitation, Bethesda, MD.

Foley, S., Marrone, J., \& Simon, M. (2002). Cruise ships and kayaks: Welfare and rehabilitation approaches for women with disabilities in poverty. Behavioral Sciences and the Law, 20(6), 659-680.

Hagner, D. \& Marrone, J. (1993). Funding Employment Under Medicaid Waiver Authority: A Necessity or a Trap?. Boston: Institute for Community Inclusion.

Hauan, S. \& Douglas, S. (2004). Potential Employment Liabilities Among TANF Recipients: A Synthesis of Data from Six State TANF Caseload Studies. Washington, DC: Department of Health and Human Services Office of the Assistant Secretary for Planning and Evaluation.

Retrieved from http//aspe os.dhhs.gov/hsp/leavers99/emp-liab04/index.htm.

Mank, D. (1994). The underachievement of supported employment: A call for reinvestment. Journal of Disability Policy Studies, 5(2), 1-24.

Marrone, J. \& Golowka, E. (2000). If you think work is bad for people with mental illness, then try poverty, unemployment, and social isolation. Psychiatric Rehabilitation Journal, $23(2), 187-193$

Marrone, J., Hoff, D., \& Gold, M. (1999). Organizational change for community employment. Journal of Rehabilitation, 65(2), 10-19.

Minnesota Department of Human Services. (1999). Minnesota Family Investment Program Longitudinal Study: Baseline Report. St. Paul: Minnesota Dept. of Human Services.

Nightingale, D.S., Pindus, N., \& Trutka, J. (2002). The Implementation of the Welfare-ToWork Grants Program. Princton, NJ: Mathematica Policy Research Inc.

Sanderson, W.C. (2002). Are evidence-based psychological interventions practiced by clinicians in the field?. Medscape Psychiatry \& Mental Health Journal, 7(1), Available at: http $/ /$ www.medscape.com/viewarticle/4I4948.

Sweeney, E.P. (2000). Recent Studies Make Clear that Many Parents Who are Current or Former Welfare Recipients have Disabilities and other Medical Conditions. Washington, DC: Center on Budget and Policy Priorities

United States General Accounting Office (GAO). (2001). Welfare reform: Moving hard to Employ Recipients into the Workforce. GAO-01-368. Washington, DC.

United States General Accounting Office (GAO). (2002a). Welfare reform: States are using TANF flexibility to adapt work requirements and time limits to meet state and local needs. Testimony before the subcommittee on Human Resources, Committee on Ways and Means, House of Representatives. Statement of Cynthia M. Fagnoni, GAO-02-501T. Washington, DC. 
United States General Accounting Office (GAO). (2002b). Welfare Reform: More Coordinated Federal Effort Could Help States and Localities Move TANF Recipients With Impairments Toward Employment. GAO-02-37. Washington, DC.

VanDeBerg, J. \& Grealish, E. (1996). Individualized services and supports through the wraparound process: Philosophy and procedures. Journal of Child and Family Studies, 5(1), $7-21$.

Washington Department of Social and Health Services. (1998). A Baseline Analysis of TANF One-Parent Families: Findings from 1997 Client Survey. Olympia: State of Washington Department of Social and Health Services, Economic Services Administration

Zedlewski, S. (1999) Work Activity and Obstacles to Work Among TANF Recipients, Series B, No. B-2. Washington, DC: Urban. Institute (http:/www.newfederalism .urban.org/html/series_b/b2/anf_b2.html).

Zedlewski, S. (2003). Work and barriers to work among welfare recipients in 2002 Snapshots of America's Families III, Number 3. Washington, DC: The Urban Institute. 